\section{Importance of Medical and Veterinary Research}

MaJor-Gein. Sir LeONARD Rogers delivered the seventh Stephen Paget Memorial lecture, entitled "The Saving in Life and Suffering due to Medical and Veterinary Research, with Special Reference to the Tropics", at the annual general meeting of the Research Defence Society held on June 22 at the London School of Hygiene and Tropical Medicine. Sir Leonard dealt with a very wide field of endeavour and conquest in the fight against the diseases of man and animals in the tropics. He outlined the advances made in the treatment of snake-bite, cholera, the dysenteries, Malta fever, relapsing fever and sleeping sickness, giving figures for the incidence and mortality rates before and after the results of research had been applied. In particular, he directed attention to the problem of typhoid fever which faced the Army medical authorities in the South African War and in the War of 1914-18 and exhibited figures proving the enormous value of protective inoculation. He forcefully reminded the audience of the services rendered by Mr. Stephen Paget, whose untiring activity both by lecturing and propaganda among our newly-recruited forces effectively countered the endeavours of anti-vivisectionists to prejudice the soldiers against anti-typhoid inoculation. Dealing with animals' diseases, Sir Leonard showed that on a conservative estimate, half a million cattle are saved annually in India as a result of preventive inoculation against rinderpest or cattle plague. $\mathrm{He}$ dealt briefly with distemper and many other diseases of animals and showed conclusively that the saving in life and suffering in animals as a direct result of research far outweighs any discomfort or pain occasioned by the necessary experiments.

\section{Experimental Study of the Nervous System}

Prof. Ross Harrison's Croonian lecture, delivered to the Royal Society on June 29, dealt with the origin and development of the nervous system studied by methods of experimental embryology. One of the early questions of importance concerned the manner in which nerve fibres reach their destination, whether by outgrowth from the young neuroblast (His's and Cajal's view) or by progressive differentiation of pre-existing protoplasmic bridges under the influence of functional activity (Hensen's view). Small pieces of embryonic nervous tissue implanted in clotted lymph outside the organism produced nerve fibres more than a millimetre in length without the intervention of other cells and in the absence of cellbridges. Conditions necessary for the outgrowth of the fibres are a suitable fluid medium, not necessarily nutritive (Lewis) and some form of solid support. By controlling the structure of the fibrin clot, through mechanical tension, the nerve fibres may be made to take more definite paths parallel to the tension lines in the fibrin and may be induced to change their course and to form plexuses (Weiss). The distribution and final connexion of the fibres are determined by the peripheral structures, as is shown by the fact that limbs grafted out of place acquire nerves from the region in which they are planted.
WHEN the area of distribution of a sensory nerve is reduced, as when a limb is prevented from developing, its ganglion becomes reduced by hypoplasia; grafting of a limb out of place is followed by hyperplasia in the spinal ganglia supplying it (as shown by Detwiler). After heteroplastic grafting, when the transplanted organ is out of scale with the rest of the animal, the nerve supply is adjusted accordingly; for example, a large tiger salamander limb grafted to a spotted salamander has correspondingly large nerves. The motor nerves are adjusted by more frequent division of the usual number of axones. The sensory nerve fibres, like the spinal ganglion cells, are actually increased in number. The nervous system during development can thus respond to a great variety of changed conditions. By further study of these responses with improved methods of experimentation, it is hoped to obtain a deeper understanding of the processes involved.

\section{Habits of the Horned Toad}

THE arrival at the Gardens of the Zoological Society of London of a horned toad (Ceratophrys ornata) is an event worth recording. This creature, a native of northern Argentina and Paraguay, where it is known as the 'Escuerzo', is one of ten species noted for their singular coloration and habits. All share the peculiarity of a bony shield underlying the skin of the back. The coloration of $C$. ornata is protective in character and of considerable beauty. The greenishyellow background is relieved by large dark green patches on the back, decreasing in size on the flanks. Each of these isolated patches is surrounded by a narrow line of white and yellow dots, interspersed with lines of rusty brown or red, producing a carpetlike pattern perfectly concealing the half-buried body. If there is not sufficient green vegetation it throws earth upon its back by the aid of the hind feet, and at the same time the skin wrinkles, and assumes a duller coloration. Extremely sluggish, it lies in wait for its victims, which include smaller members of its own species, as well as frogs, which are said to form its staple diet. Horned toads are said to inflate the body when angry, and to hop backwards and forwards uttering a succession of loud cries, hence they are also known as 'crying frogs'. As the cause of their excitement is removed, they slowly deflate the body and relapse into the stony silence enjoined by the need of fresh victims. During the dry season, like many other batrachians living in hot countries, they æstivate.

\section{An Unusual Rainbow Phenomenon}

AN account has been received from Mr. J. L. Horton, 103 Colworth Road, Leytonstone, London, E.11, of an unusual rainbow phenomenon observed between 8.20 and 8.30 p.m. on June 26. There was a primary bow of the usual kind (violet nearest to the sun), and a secondary bow farther from the sun (with colours reversed). Unusual features were two fainter and narrower bows; one lay immediately adjoining the primary bow on its inner side, with colours arranged in the same order ranging from 